\title{
THE DOUBLE CALIPER
}

\section{N. B. LangBalle}

$\mathbf{T}$

HE principle of this instrument was developed in Denmark by a Colonel Prytz and the writer is only explaining it in English, which he believes has not been done before.

The usual way of getting the average diameter of a stand is to measure each tree.

By using the law of error this result can be obtained in an easier way.

To understand the principle the following must be borne in mind. If you measure a thing a number of times you will not always get the same result. Supposing you have measured the angles in a triangle a great number of times, the results will group themselves around 180. If your instrument is fine enough there will always be differences due to accidental errors. From this we can calculate the standard deviation "v." To tabulate this information

\section{DOUBLE CALIPER}

$S C A \angle E: I^{\prime}=10^{\prime}$

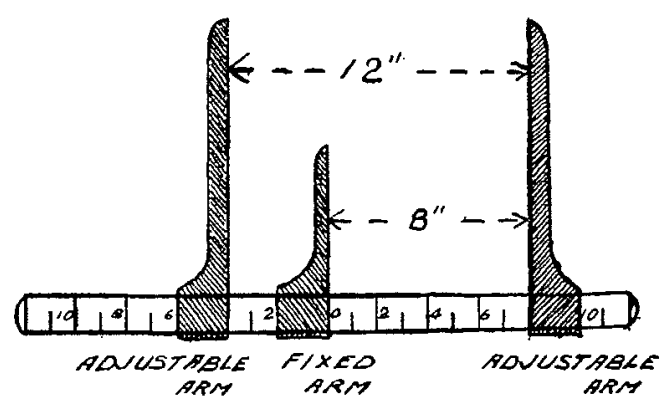

we will divide the absissa in a system of cordinates into fractions of the standard deviation. Let us for instance choose the intervals $1 / 4 \mathrm{v}$. Over these intervals we will draw rectangles representing in area the percentage of the differences falling in each interval. If we connect the middle of the tops of these rectangles with a line we will get a curve showing the distribution of errors. This is obviously dependent only on the size of the standard deviation " $v$," and of the percentage of errors in each interval. It can be shown, however, that the latter of these two factors is the same for all measurements. This can be proved by higher mathematics and a very intricate equation given for the curve. It can also be proved by taking a great number of measurements of a great number of different things and plotting the results as above.

So far we have considered only the accidental errors in measuring. The law applies however to all deviations from a standard. Thus it also holds 
good for the differences in diameter between the average tree and the individual tree in a stand.

If you measure all the trees in a stand you can find the deviation of the individual trees from the diameter of the average tree, and consequently the standard deviation. But, when we know that these will follow a certain law, isn't it possible to use this law and derive the diameter of the average tree by a shorter method?

By dividing the trees into three groups it can be proved that this is possible. One group must be below a certain diameter limit. A second group must be between this diameter limit and another higher diameter limit. A third group must be above the second diameter limit.

From the curve mentioned above we can get the probability of the oc. currence of a certain deviation from standard, when this is expressed in multiples of the standard deviation. A table giving this information is shown below.

\begin{tabular}{lccccccr}
\hline \hline $\begin{array}{l}\text { Multiple of } \\
\text { standard } \\
\text { deviation }\end{array}$ & $\begin{array}{c}\% \text { of } \\
\text { probability }\end{array}$ & $\begin{array}{c}\text { Mul. of } \\
\text { stan. } \\
\text { dev. }\end{array}$ & $\begin{array}{c}\% \text { of } \\
\text { prob. }\end{array}$ & $\begin{array}{c}\text { Mul. of } \\
\text { stan. } \\
\text { dev. }\end{array}$ & $\begin{array}{c}\% \text { of } \\
\text { prob. }\end{array}$ & $\begin{array}{c}\text { Mul. of } \\
\text { stan. } \\
\text { dev. }\end{array}$ & $\begin{array}{r}\% \text { of } \\
\text { prob. }\end{array}$ \\
\hline .1 & 8.0 & .6 & 45.1 & 1.2 & 77.0 & 2.5 & 98.8 \\
.2 & 15.9 & .7 & 51.6 & 1.4 & 83.8 & 3.0 & 99.7 \\
.3 & 23.6 & .8 & 57.6 & 1.6 & 89.0 & 3.5 & 99.95 \\
.4 & 31.1 & .9 & 63.2 & 1.8 & 92.8 & 4.0 & 99.99 \\
.5 & 38.3 & 1.0 & 68.2 & 2.0 & 95.4 & & 100.00 \\
\hline
\end{tabular}

The best way of illustrating the use of this method is by an example. Supposing you have counted your trees and found the following:-

Diameter less than 8 in. ................. 36

Diameter less than 16 in. but over 8 in. ........ 165

Diameter over 16 in. .................. 39

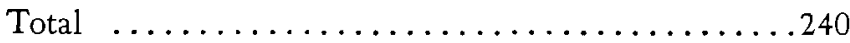

The average diameter is unknown and can be called $\mathrm{x}$. To find the probability of a tree having a deviation from $x$ larger than $(x-8)$ in. we have the following:-

$$
\text { Probability }(\mathrm{p})=100 \%-\frac{2 \times 36 \times 100 \%}{240}=70.0 \%
$$

We have to multiply our 36 trees by two as there are as many trees above $x$ with a deviation of $(x-8)$ in. as there are below, but we have only counted the latter. In the same manner we find the probability of a tree having a deviation from $x$ of more than $(16-x)$ in., which in this case will be:-

Probability $(p)=100 \%-2 \times 39 \times 100 \% \quad 67.5 \%$ 
From our table we get the values of the multiples of the standard deviation corresponding to the percentages. These are in our case 1.039 and 0.984 . This means that our differences $(x-8)$ in. is 1.039 times the standard deviation and that our difference $(16 \cdot x)$ in. is 0.984 times the standard deviation. Consequently we have, calling the standard deviation "v:"

$$
\begin{aligned}
1.039 \mathrm{v} & =\mathrm{x}-8 \\
0.984 \mathrm{v} & =16 \mathrm{x} \\
\hline 2.023 \mathrm{v} & =8 \\
\mathrm{v} & =3.95 \\
\hline \mathrm{x} & =1.039 \times 3.95+8=4.1+8=12.1 \text { in. } \\
\mathrm{x} & =16-0.984 \times 3.95=16-3.9=12.1 \text { in. }
\end{aligned}
$$

Thus the diameter 12.1 in. will be the desired result.

To divide the trees into groups you use a "Double Caliper," from which the method is named. It consists of a bar with one fixed and two adjustable arms. You adjust the arms on each side of the fixed one to the desired diameter limits and have then a measure you can use for dividing the trees into groups. In most cases it is not necessary to put the caliper on the tree, you can judge by eye to which group the tree belongs. It is recommended to choose the diameter limits so that the ratio between the groups is about $1: 4: 1$.

It is not necessary to recommend the method for special cases. It should be used along with other methods as the forest engineer thinks it most suitable.

It is undoubtedly a rather exact method, especially when used for a large number of trees. While not as fast as the "Partial Count Method" developed by the late H. R. Wickenden, it is more exact. On the other hand it is faster than measuring each tree but not as accurate.

The same principle can of course be applied to the measuring of logs or the length of trees, etc. As mentioned it is one of the fundamental laws and is to be met everywhere. 